to identify TRPM8 (ref. 14; the same channel as that identified by Julius's group, but with a different name) as a cold receptor. Beginning with a bioinformatics approach, Peier et al. isolated new members of the TRP family, including TRPM8. In situ hybridization experiments and functional studies then showed that this channel is a cold receptor expressed in a subset of somatosensory neurons that detect temperature and noxious stimuli.

CMR1/TRPM8 has some intriguing properties. It shows pronounced outward rectification - ions flow more readily in the

\title{
Biogeochemistry
}

\section{That's life?}

This could be a picture of one of the earliest-known fossils a microbe, $60 \mu \mathrm{m}$ long, that is almost 3,500 million years old. On the other hand, it could be just a flaw in the rock. It all depends on whom you talk to, as epitomized by two papers in this issue.

The more optimistic view is taken by William Schopf and colleagues (Nature 416, 73-76; 2002). In the early 1990s, Schopf caused a sensation with reports of a diverse bacterial flora from the 3,465-millionyear-old Apex cherts of Western Australia. At the time, all he had to go on was morphology. This was always controversial, given that bacteria have little morphology to begin with. As a consequence, it is hard to tell the difference between a bacterium - especially a fossil bacterium - and a bubble. This is why Schopf has devised authenticity criteria that are based on bacterial habit. If you have one bacterium, for example, you will usually have hundreds: isolated blobs purporting to be bacteria usually turn out to be artefacts. Since then, Schopf and colleagues have sought to back up the morphology using laser-Raman imaging, a technique in which the chemical composition, as well as the structure of the fossils, can be mapped in two dimensions. After several tests of the technique on less controversial fossils, Schopf $e t$ al. have used the method on the Apex chert material. They find that the fossils have the composition to be expected if they were made of organically derived carbon.

This will not be the end of

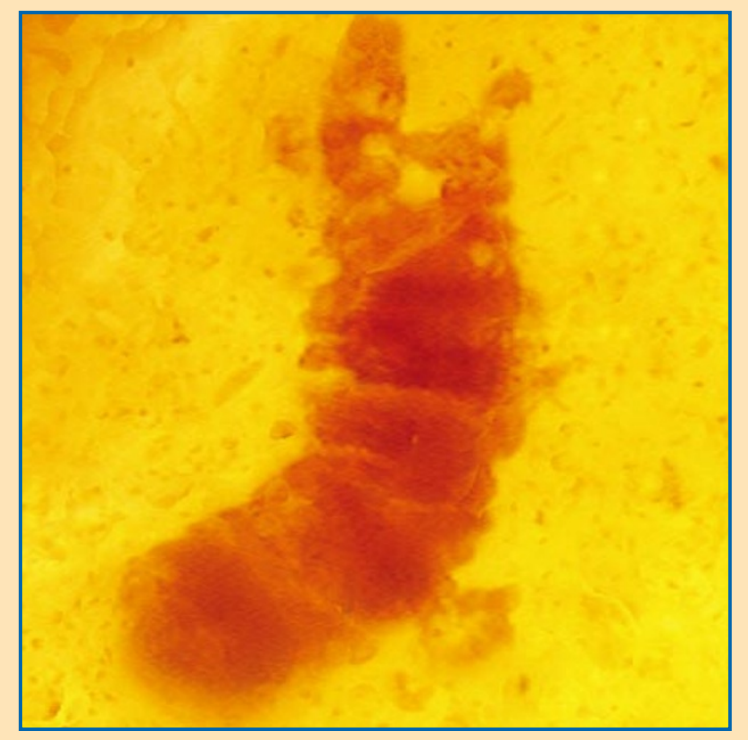

the controversy, however, as demonstrated by the report from Martin Brasier and colleagues (Nature 416, 76-81; 2002). Using the original Apex chert material, as well as newly collected specimens, they find that the rocks in which the fossils were found come from a vein that may have been produced hydrothermally, that is, by the action of heated water on minerals. The carbonisotope signature is consistent with a biogenic origin, one derived from living organisms. But other studies suggest that this was an environment in which carbon dioxide produced by volcanic action was transformed into isotopically light carbon at $250-350^{\circ} \mathrm{C}$.

The bottom line is that although the carbon looks organic, it need not be. Similarly, Raman spectroscopy shows that although the material in the fossils could be biogenic, it could equally well be amorphous graphite.

Brasier et al. even dismiss the morphology. They suggest that the fossils, as a whole, have a random orientation that is not characteristic of bacterial behaviour, in which the cells tend to line up in one direction or another; the individual cells have a range of strange, even branched, morphologies; and what look like filaments with internal divisions may be the result of interleaving quartz and graphite sheets. Many authors agree that there is isotopic evidence for biogenic activity in the Archaean (that interval of Earth history before 2,500 million years ago). But Brasier and colleagues, at least, say that the Apex chert fossils aren't really fossils at all.

Given that Schopf was one of the first to cast doubt on the biogenicity of another celebrated suite of purported microfossils - in the martian meteorite ALH84001 - it is ironic that his own work should be subjected to such scepticism. But that is the name of the game for claims of life at the extremes of time and space. Henry Gee outward direction - and has relatively high permeability for $\mathrm{Ca}^{2+}$ ions, with little selectivity between monovalent cations (it is a non-selective cation channel). Interestingly, the channel desensitized after exposure to either cold stimuli or menthol, but the adaptation to cold temperatures could be reversed after warming to room temperature. Furthermore, cold responses were enhanced by menthol, but menthol could not stimulate the channel at warm temperatures. Thus, cold temperatures may be activating this channel by triggering progressive conformational shifts between the open and closed states, and menthol could be viewed as an allosteric modulator - it shifts the channels' activation threshold to less cold temperatures.

The discovery of a cold receptor opens the way to answering many of the outstanding questions in the field. For example, does CMR1/TRPM8 work in concert with other ion channels on the surface of temperaturesensitive neurons to shape responses to cold stimuli $^{6-9}$ ? Does the channel participate in pain pathways, and do other physiological stresses, such as the components of the 'inflammatory soup' produced by tissue injury, modulate its function? More generally, we can now start to explore how responses to warmth and cold are choreographed at the molecular level, and how the temperature spectrum is encoded and decoded by the nervous system. The next goals should be to finely map the sites of expression of the various receptors; to trace the connectivity patterns of the corresponding neurons to the spinal cord and brain; and to examine the physiological and behavioural effects of knocking out specific receptors and channels in model organisms.

Charles S. Zuker is at the Howard Hughes

Medical Institute and Departments of

Biology and Neurosciences, University

of California at San Diego, La Jolla,

California 92093-0649, USA.

e-mail: charles@flyeye.ucsd.edu

1. McKemy, D. D., Neuhausser, W. M. \& Julius, D. Nature

416, 52-58 (2002); online 10 February 2002

(DOI 10.1038/nature719).

2. Peier, A. et al. Cell online 11 February 2002

(DOI 10.1016/S0092867402006529).

3. Caterina, M. J. et al. Nature 389, 816-824 (1997).

4. Caterina, M. J. et al. Nature 398, 436-441 (1999).

5. Julius, D. \& Bausmam, A. I. Nature 413, 203-210 (2001).

6. Askwith, C. C. et al. Proc. Natl Acad. Sci. USA 98, 6459-6463 (2001).

7. Pierau, F. K., Torrey, P. \& Carpenter, D. O. Brain Res. 73, 156-160 (1974).

8. Carpenter, D. O. Fed. Proc. 40, 2808-2813 (1981).

9. Viana, F., de la Peña, E. \& Belmonte, C. Nature Neurosci. 5 , 254-260 (2002); online 11 February 2002 (DOI 10.1038/nn809)

10. Reid, G. \& Flonta, M. L. Nature 413, 480 (2001).

11. Hemsel, H. \& Zotterman, Y. Acta Physiol. Scand. 24, 27-34 (1951).

12. Clapham, D. E., Runnels, L. W. \& Strubing, C. Nature Rev. Neurosci. 2, 387-396 (2001).

13. Chen, C. C., Rainville, P. \& Bushnell, M. C. Pain 68, 33-43 (1996).

14. Tsavaler, L. et al. Cancer Res. 61, 3760-3769 (2001). 